Check for updates

Cite this: RSC Adv., 2018, 8, 10246

Received 27th January 2018

Accepted 23rd February 2018

DOI: $10.1039 / c 8 r a 00842 f$

rsc.li/rsc-advances

\section{Design, synthesis and characterization of a novel bluish-green long-lasting phosphorescence phosphor $\mathrm{BaLu}_{2} \mathrm{Si}_{3} \mathrm{O}_{10}: \mathrm{Eu}^{2+}, \mathrm{Nd}^{3+}$}

\author{
Jie Liu, ${ }^{a b}$ Gen Li, ${ }^{a b}$ Haijie Guo, ${ }^{\text {ab }}$ Dongwei Liu, ${ }^{a b}$ Peng Feng ${ }^{a b}$ and Yuhua Wang (DD *ab
}

Through drawing upon a solid-state reaction, a newly proposed long-lasting phosphor $\mathrm{BaLu}_{2} \mathrm{Si}_{3} \mathrm{O}_{10}: \mathrm{Eu}^{2+}$, $\mathrm{Nd}^{3+}$ is presented and prepared in this work. The thermoluminescence properties of the phosphor are substantially extended, and the long-lasting phosphorescence behavior is markedly intensified by virtue of the consolidation of $\mathrm{Nd}^{3+}$ ions which serve as trap centers. In line with density functional theory calculations, the conduction band is mostly composed of Lu $5 d$ states while the Ba $5 d$ states only have a tiny contribution. We analyzed the relationship between the phosphor's electronic structure and its optical properties. The photoluminescence emission spectrum shows a blue emitting band with a wide asymmetric property and an extremum of $426 \mathrm{~nm}$, arising from the $5 \mathrm{~d}-4 \mathrm{f}$ transitions of the $\mathrm{Eu}^{2+}$ ions which occupy the $\mathrm{Ba}$ and Lu sites. It is asserted that the long-lasting phosphorescence of the $\mathrm{Eu}^{2+}$ ions which take up both $\mathrm{Ba}$ and Lu sites stems from the special form of conduction band and the occupying environment of the emission center. Yet, they have different contributions and induce an interesting phenomenon in which the blue emitting phosphor shows a bluish-green phosphorescence. The longlasting phosphorescence can last in excess of $6 \mathrm{~h}$ at the recognized intensity level $\left(0.32 \mathrm{mcd} \mathrm{m}^{-2}\right)$ after excitation for $10 \mathrm{~min}$. This work provides a new way of thinking for the development of multicolored LLP materials. This work analyzes and sheds light on the specific courses and provides a likely mechanism for the process.

\section{Introduction}

Long-lasting phosphorescence (LLP) is an optical phenomenon of great significance. Luminescence can be observed after ceasing the excitation after a couple of minutes and probably persists over a longer period of time of several hours. ${ }^{1,2}$ Under excitation, energy can be stored and absorbed by LLP materials (inclusive of artificial light and sunlight). Subsequently, the stored and absorbed energy can be released as persistent visible light under thermal stimulation, commonly at room temperature. ${ }^{3,4}$ LLP materials have aroused considerable attention and have been applied in extensive important fields by virtue of its prominent characteristics which include being recyclable, energy saving, and eco-friendly. ${ }^{5}$ Initially, LLP materials were adopted for night-time displays, traffic signs, in or on buildings, in public places, for emergency signs, and security signs. ${ }^{6}$ Additionally, the foregoing materials have been adopted in structural damage sensors, radiation detectors, and optical storage media. ${ }^{7}$ Thus far, LLP materials have been adopted in

${ }^{a}$ Department of Materials Science, School of Physical Science and Technology, Lanzhou University, Lanzhou, 730000, PR China. E-mail: wyh@lzu.edu.cn; Fax: +86931 8913554; Tel: +869318912772

${ }^{b}$ Key Laboratory for Special Function Materials and Structural Design of the Ministry of Education, Lanzhou University, Lanzhou 730000, China a growing number of fields to address relevant challenges, such as in in vivo bio-imaging, medical diagnostics and solar energy utilization, etc. $^{8}$

Moreover, large numbers of LLP materials have been developed and reported. LLP materials colored red, green and blue are primarily highlighted and discussed with a predominant amount of the research reported adopting these materials for a particular purpose. Theoretically, any color material can be attained through blending these three predominant colors and changing their proportions. ${ }^{9-12}$ Yet, implementing the mentioned approach is difficult. Although two of the tricolor LLP materials, blue $\left(\mathrm{CaAl}_{2} \mathrm{O}_{4}: \mathrm{Eu}^{2+}, \mathrm{Nd}^{3+},>24 \mathrm{~h}\right)$ and green $\left(\mathrm{SrAl}_{2} \mathrm{O}_{4}: \mathrm{Eu}^{2+}, \mathrm{Dy}^{3+},>24 \mathrm{~h}\right)$, are very bright and can be adopted for use in the market, red LLP materials are overall inadequate when adopted for a particular purpose. ${ }^{13,14}$ Making the various components consistent with each other during the phosphorescent decay can be hard and ensuring that the color of the phosphorescence is uniform can be difficult. Furthermore, a single source of excitation can be inefficient in exciting the majority of LLP materials. ${ }^{15,16}$

In this regard, newly proposed LLP materials consisting of multiple colors will be critically and urgently explored and developed. Currently, there is a growing interest in silicatebased luminescent materials due to their excellent chemical stability, thermal stability, weather resistance, and low 
temperature synthesis. ${ }^{\mathbf{1 7}, 18}$ In 2010, M. Wierzbicka-Wieczorek et al. initially developed and reported the trisilicates $\mathrm{BaRe}_{2} \mathrm{Si}_{3}$ $\mathrm{O}_{10}(\mathrm{Re}=\mathrm{Sc}, \mathrm{Yb}, \mathrm{Er}$, and $\mathrm{Gd}) .{ }^{19}$ The topological structure of the $\mathrm{BaRe}_{2} \mathrm{Si}_{3} \mathrm{O}_{10}$ trisilicates consists of trisilicate $\mathrm{Si}_{3} \mathrm{O}_{10}$ groups in the shape of a horseshoe and $\mathrm{ReO}_{6}$ octahedra distorted by zigzag chains of edge-sharing. Subsequently, the foregoing trisilicate compounds, e.g. $\mathrm{BaSc}_{2} \mathrm{Si}_{3} \mathrm{O}_{10}$ and $\mathrm{BaY}_{2} \mathrm{Si}_{3} \mathrm{O}_{10}$ are adopted to synthesize numerous versatile lanthanon doped phosphors. Additionally, the application of these phosphors in white LEDs has been investigated, as well as their photoluminescent properties. ${ }^{20-24}$ In 2014, the bivalent $\mathrm{Eu}^{2+}$ doped $\mathrm{BaM}_{2} \mathrm{Si}_{3} \mathrm{O}_{10}: \mathrm{Eu}^{2+}(\mathrm{M}=\mathrm{Sc}, \mathrm{Lu})$ phosphor was prepared and proposed by Jakoah Brgoch et al. ${ }^{25}$ In 2016, Kai Li et al. reported the preparation and photoluminescent properties of the tervalent $\mathrm{Ce}^{3+}$ and $\mathrm{Tb}^{3+}$ co-doped $\mathrm{BaLu}_{2} \mathrm{Si}_{3} \mathrm{O}_{10}$ phosphor. ${ }^{26}$ The $\mathrm{BaLu}_{2} \mathrm{Si}_{3} \mathrm{O}_{10}$ phosphor has prominent luminescence properties, which has aroused massive research interest. Until now, as indicated by a literature review, no papers have studied the LLP properties of this phosphor. Traps are significant for photoenergy storage of persistent and thermo-stimulated phosphors. Suitable trap depths and trap densities are beneficial for improving LLP properties. Co-doping $\mathrm{Re}^{3+}$ ions counts as one of the most frequently adopted approaches to generate new traps or update the internal properties of traps arising from nonequivalent substitution. As Dorenbos' theory indicates that $\mathrm{Nd}^{3+}$ ions count as adequate traps, $\mathrm{Nd}^{3+}$ ions are deemed trap centers and can be incorporated into $\mathrm{BaLu}_{2} \mathrm{Si}_{3} \mathrm{O}_{10}: \mathrm{Eu}^{2+}$ hosts. ${ }^{27}$ Based on the above reasons, we have synthesized a LLP BaLu $2^{-}$ $\mathrm{Si}_{3} \mathrm{O}_{10}: \mathrm{Eu}^{2+}, \mathrm{Nd}^{3+}$ phosphor. In this work, the electronic structure, photoluminescence, and phosphorescence properties of this phosphor are investigated systematically and shed light on.

\section{Experimental}

\subsection{Synthesis}

Following a frequently adopted method using high-temperatures in the solid state, this work fabricated the desired samples $\mathrm{Ba}_{1-2 x} \mathrm{Lu}_{2} \mathrm{Si}_{3} \mathrm{O}_{10}: x \mathrm{Eu}^{2+}, x \mathrm{Nd}^{3+}(x=0,0.004,0.006,0.008,0.010 .02$ and 0.03 , respectively presented as $\mathrm{S} 1$ to $\mathrm{S} 6)$ whereby the raw materials were $\mathrm{Eu}_{2} \mathrm{O}_{3}$ (99.99\%), $\mathrm{Nd}_{2} \mathrm{O}_{3}$ (99.99\%), $\mathrm{SiO}_{2}$ (99.99\%), and $\mathrm{BaCO}_{3}$ (99.99\%). The relative raw materials were mixed in stoichiometric amounts and intensively ground uniformly in an agate mortar for $40 \mathrm{~min}$, while incorporating an adequate amount of ethanol. The mixture was placed in alumina crucibles and sintered for $5 \mathrm{~h}$ at $1400{ }^{\circ} \mathrm{C}\left(\mathrm{N}_{2}: \mathrm{H}_{2}=95: 5\right)$ in a reducing atmosphere in a tube furnace powered by electricity. After calcining, the temperature of the samples was reduced within the furnace to room temperature and ground a second time for further application.

\subsection{Characterization}

These samples were characterized by powder X-ray diffraction (XRD) using a Rigaku diffractometer featuring Ni-filtered $\mathrm{Cu} \mathrm{K \alpha}$ radiation at scanning steps of $0.02^{\circ}$ with the $2 \theta$ value ranging from $10^{\circ}$ to $80^{\circ}$. This enabled the overall phase structures of the samples to be examined. Through employing a F30 S-TWIN electron microscope (Tecnai ${ }^{\mathrm{TM}} \mathrm{G} 2$, FEI Company) highresolution transmission electron microscopy (HRTEM) images, transmission electron microscopy (TEM) images, and an energy dispersive X-ray spectroscopy (EDX) spectrum were attained. Using a UV-Vis spectrophotometer (PE Lambda 950) and a sample of $\mathrm{BaSO}_{4}$ an ultraviolet-visible (UV-vis) diffuse reflectance spectra (DRS) was attained and used as a reference. A Xe-900 xenon arc lamp $(450 \mathrm{~W})$, with a FLS-920T fluorescence spectrophotometer as the source of excitation, was used to measure the luminescence decay curves, the LLP spectra, the photoluminescence excitation (PLE), and the photoluminescence emission (PL). $1 \mathrm{~nm}$ was established as the scanning step. 10 min after irradiating the samples with ultraviolet light a PR305 long afterglow instrument was used to measure the decay curve of the LLP. TL curves were provided using a FJ-427A TL meter (Beijing Nuclear Instrument Factory) with a heating rate of $1 \mathrm{~K} \mathrm{~s}^{-1}$ and a temperature range of 20 to $400{ }^{\circ} \mathrm{C}$. In this work, UV light was used to irradiate $0.0020 \mathrm{~g}$ samples which had been pressed into pellets for 5 min prior to measuring. The photographs of $\mathrm{BaLu}_{2} \mathrm{Si}_{3} \mathrm{O}_{10}: \mathrm{Eu}^{2+}$ and $\mathrm{BaLu}_{2}-$ $\mathrm{Si}_{3} \mathrm{O}_{10}: \mathrm{Eu}^{2+}, \mathrm{Nd}^{3+}$ under/after UV irradiation were taken in a dark room by a common digital camera with certain parameter settings (exposure time, ISO value, and aperture value). With the exception of the TL curves, these measurements were conducted at room temperature. Through using the CASTEP code and abiding by density functional theory, this work calculated the electronic structure adopted by $\mathrm{BaLu}_{2} \mathrm{Si}_{3} \mathrm{O}_{10}$. Among the theories of density function, this work selected the local-density approximations (LDA).

\section{Results and discussion}

\subsection{XRD patterns and Rietveld refinement}

$\mathrm{XRD}$ was used to ascertain the phase purity adopted by the prepared samples. Given that the structure of $\mathrm{BaLu}_{2} \mathrm{Si}_{3} \mathrm{O}_{10}$ has never previously been proposed in literature, this work references the crystallographic data and initial model structure with the purpose of refining them for $\mathrm{BaYb}_{2} \mathrm{Si}_{3} \mathrm{O}_{10}$ (ICSD 17781). The representative XRD patterns for the relative samples are presented in Fig. 1a (S1-S6). All of the diffraction peaks are used as a standard reference for the $\mathrm{BaYb}_{2} \mathrm{Si}_{3} \mathrm{O}_{10}$ (ICSD 17781) compound. ${ }^{26}$ No impure phases were detected in the attained samples, which indicates that a single phase is taken up by all of the attained samples, and the $\mathrm{Eu}^{2+}$ and $\mathrm{Nd}^{3+}$ ions are successfully incorporated into the $\mathrm{BaLu}_{2} \mathrm{Si}_{3} \mathrm{O}_{10}$ host. The XRD pattern of the $\mathrm{BaLu}_{2} \mathrm{Si}_{3} \mathrm{O}_{10}$ host is presented in Fig. $1 \mathrm{~b}$ on the basis of the Rietveld structural refinement which was attained using the Materials Studio program. The background, the experimental pattern and the calculated pattern are denoted by a yellow solid line, black crosses, and a red solid line, respectively. The Bragg reflection positions taken up by the acquired pattern are indicated by short vertical pink lines. At the bottom, the blue line shows how the calculated and experimental results are different from each other. Rietveld refinement effectively examines how atoms are positioned in a primitive cell. The residual factors are $R_{\mathrm{wp}}=13.78 \%, R_{\mathrm{p}}=9.75 \%$ and $\chi^{2}=3.127$, which demonstrate that the refined results are reliable. The refinement results 

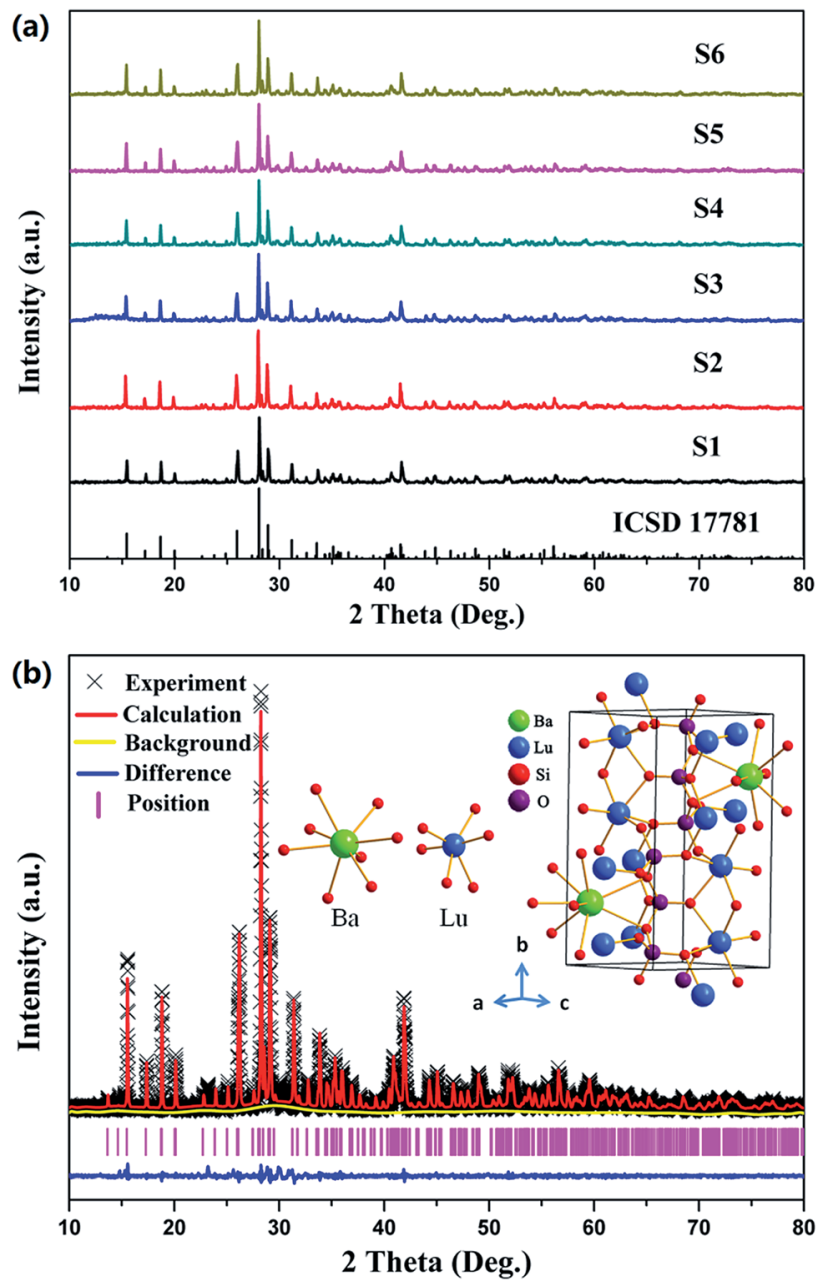

Fig. 1 (a) XRD patterns for $\mathrm{Ba}_{1-2 x} \mathrm{Lu}_{2} \mathrm{Si}_{3} \mathrm{O}_{10}: x \mathrm{Eu}^{2+}, x \mathrm{Nd}^{3+}(x=0,0.004$, $0.006,0.008,0.010 .02$ and 0.03 ). (b) XRD refinement and the crystal structure of the $\mathrm{BaLu}_{2} \mathrm{Si}_{3} \mathrm{O}_{10}$ host.

confirm that the compound is in the monoclinic space group $P 2_{1} / m$ (no. 11) with cell parameters $a=5.3541(1) \AA, b=$ 12.1224(3) $\AA$, and $c=6.7829(2) \AA$. The final refinement results indicate that this phosphor has two diverse cations, namely 8coordinated $\mathrm{Ba}^{2+}(r=1.42 \AA)$ and 6-coordinated $\mathrm{Lu}^{3+}(r=0.861$ $\AA)$, presented in Fig. 1b. Distorted $\mathrm{SiO}_{4}$ tetrahedra which form corner-sharing zig-zag trimers are contained in the crystal structure. Two $\mathrm{Si}^{4+}$ cations are given which are crystallographically independent. Through adopting two highly distorted edge-sharing $\mathrm{LuO}_{6}$ octahedra, this work connects the foregoing $\mathrm{SiO}_{4}$ trimers. ${ }^{27}$ Generally, the radii difference between the two cations primarily determines whether the doped ions can substitute for the host cation. ${ }^{25}$ The percentage difference in ionic radii between the substituted and the doped ions should be less than $30 \% .{ }^{28}$ The equation below can calculate the difference between the possible substituted ions $\left(\mathrm{Ba}^{2+}, \mathrm{Lu}^{3+}\right)$ and the doped rare ions $\left(\mathrm{Eu}^{2+}, \mathrm{Nd}^{3+}\right)$ in radius percentage. ${ }^{29}$

$$
\mathrm{Dr}=100 \times[\mathrm{Rm}(\mathrm{CN})-\mathrm{Rd}(\mathrm{CN})] / \mathrm{Rm}(\mathrm{CN})
$$

Table 1 The radius and $\mathrm{Dr}$ values between $\mathrm{Eu}^{2+} / \mathrm{Nd}^{3+}$ and $\mathrm{Ba}^{2+} / \mathrm{Lu}^{3+}$

\begin{tabular}{lll}
\hline & $\mathrm{CN}=8$ & $\mathrm{CN}=6$ \\
& $\mathrm{Ba}^{2+}, R=1.420 \AA$ & $\mathrm{Lu}^{3+}, R=0.861 \AA$ \\
\hline $\mathrm{Eu}^{2+}$ & $R=1.250 \AA$ 列 $=12 \%$ & $R=1.170 \AA, \mathrm{Dr}=35 \%$ \\
$\mathrm{Nd}^{3+}$ & $R=1.109 \AA, \mathrm{Dr}=22 \%$ & $R=0.983 \AA, \mathrm{Dr}=14 \%$
\end{tabular}

where $\mathrm{Dr}$ is the radius percentage difference; $\mathrm{CN}$ is the coordination number; $\mathrm{Rm}(\mathrm{CN})$ is the radius of the host cation; and $\mathrm{Rd}(\mathrm{CN})$ is the radius of the doped ion. The radii and calculated values of $\mathrm{Dr}$ between $\mathrm{Eu}^{2+} / \mathrm{Nd}^{3+}$ and $\mathrm{Ba}^{2+} / \mathrm{Lu}^{3+}$ are shown in Table 1. In light of calculated results from empirical equations, it can be deduced that $\mathrm{Nd}^{3+}$ ions could enter into both Ba and Lu sites while $\mathrm{Eu}^{2+}$ ions only seem to enter into the Ba sites.

\subsection{Scanning electron microscopy and transmission electron microscopy analyses}

The morphology of the two selected $\mathrm{BaLu}_{2} \mathrm{Si}_{3} \mathrm{O}_{10}$ host and $\mathrm{BaLu}_{2} \mathrm{Si}_{3} \mathrm{O}_{10}: \mathrm{Eu}^{2+}, \mathrm{Nd}^{3+}$ samples was detected using SEM technology. As shown in Fig. 2a and c, the morphologies of these two samples are similar to each other. As shown, the blocky particles are irregularly shaped and approximately $2-10 \mu \mathrm{m}$ in size, making their form and structure suitable for the fabrication of phosphors. The elemental composition of the $\mathrm{BaLu}_{2} \mathrm{Si}_{3} \mathrm{O}_{10}$ host was investigated by EDX spectroscopy and the spectrum is shown in Fig. 2b. It confirms the presence of $\mathrm{Ba}, \mathrm{Lu}, \mathrm{Si}$, and $\mathrm{O}$ in the $\mathrm{BaLu}_{2} \mathrm{Si}_{3} \mathrm{O}_{10}$ sample. The elements of $\mathrm{C}$ and $\mathrm{Cu}$ come from the carbon membrane. The distance between the crystal planes reaches $0.325 \mathrm{~nm}$, which is consistent with the (002) planes of
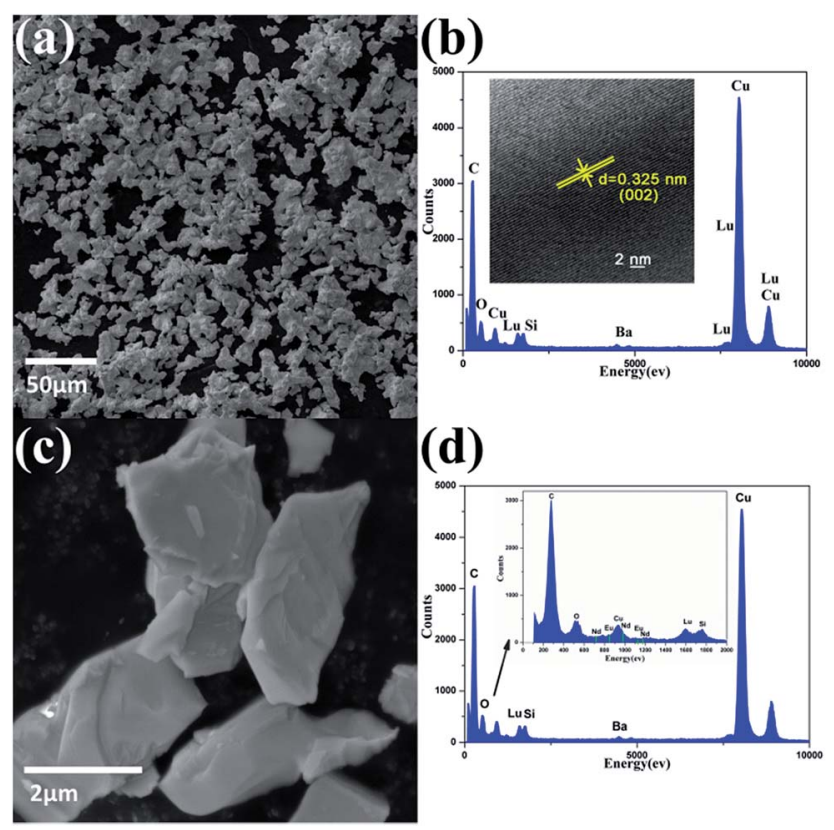

Fig. 2 (a) SEM images of the $\mathrm{BaLu}_{2} \mathrm{Si}_{3} \mathrm{O}_{10}$ host. (b) EDX spectrum of the $\mathrm{BaLu}_{2} \mathrm{Si}_{3} \mathrm{O}_{10}$ host. (Inset) HRTEM images of the $\mathrm{BaLu}_{2} \mathrm{Si}_{3} \mathrm{O}_{10}$ host. (c) $\mathrm{SEM}$ images of $\mathrm{BaLu}_{2} \mathrm{Si}_{3} \mathrm{O}_{10}: \mathrm{Eu}^{2+}, \mathrm{Nd}^{3+}$. (d) EDX spectrum of $\mathrm{BaLu}_{2}-$ $\mathrm{Si}_{3} \mathrm{O}_{10}: \mathrm{Eu}^{2+}, \mathrm{Nd}^{3+}$. (Inset) Regional area with high resolution. 
$\mathrm{BaLu}_{2} \mathrm{Si}_{3} \mathrm{O}_{10}$ in Fig. 2b (inset). ${ }^{30}$ In addition, the elemental composition of $\mathrm{BaLu}_{2} \mathrm{Si}_{3} \mathrm{O}_{10}: \mathrm{Eu}^{2+}, \mathrm{Nd}^{3+}$ was also investigated by EDX spectroscopy with the spectrum shown in Fig. 2d. As shown in Fig. 2d (inset), the elements of Eu and $\mathrm{Nd}$ are also detected.

\subsection{Band structure}

Fig. 3a-d show the computations of $\mathrm{BaLu}_{2} \mathrm{Si}_{3} \mathrm{O}_{10}$ abiding by the density functional theory and on the basis of the crystal structure refinement. This paper selects the LDA as the theoretical basis of the density function. The relevant compound takes on an indirect bandgap which reaches approximately $4.843 \mathrm{eV}$, with the conduction band (CB) peaking at the $\mathrm{G}$ point and the valence band (VB) peaking at the $\mathrm{D}$ point of the Brillouin zone, which suggests that this is an appropriately wide bandgap for $\mathrm{Eu}^{2+}$ to serve as a center to emit light and for $\mathrm{Nd}^{3+}$ to serve as a trap center. The electronic structure taken on by the valence band primarily stems from $\mathrm{O} 2 \mathrm{p}$ states, whereas the conduction band is mostly encompassed by $\mathrm{Lu} 5 \mathrm{~d}$ states. It is worth mentioning that $\mathrm{Ba} 5 \mathrm{~d}$ states also have a tiny contribution to the conduction band. This special band structure characteristic has great effects on the phenomena of photoluminescence and phosphorescence.

\subsection{UV-visible diffuse reflectance spectrum}

Fig. 4 shows the DRS of the undoped $\mathrm{BaLu}_{2} \mathrm{Si}_{3} \mathrm{O}_{10}$ host and concentration gradient samples of $\mathrm{BaLu}_{2} \mathrm{Si}_{3} \mathrm{O}_{10}: \mathrm{Eu}^{2+}$. For the host, the absorption in the ultraviolet region ranging from 200 to $400 \mathrm{~nm}$ arises from the valence-to-conduction band. For the samples of $\mathrm{BaLu}_{2} \mathrm{Si}_{3} \mathrm{O}_{10}: \mathrm{Eu}^{2+}$, the feature absorbance peaks of $290 \mathrm{~nm}$ and $325 \mathrm{~nm}$ are consistent with the excitation peaks as shown in Fig. 5a, which are attributed to the $\mathrm{Eu}^{2+}$ ions. The observed white color of the sample is a consequence of the spectral range being in the visible region. Kubelka-Munktransformed DRS of the $\mathrm{BaLu}_{2} \mathrm{Si}_{3} \mathrm{O}_{10}$ host, in line with the formula of $[F(R) \times h \nu]^{n}=A\left(h \nu-E_{\mathrm{g}}\right)$, is presented in the inset of Fig. 4 where $F(R)$ is the Kubelka-Munk function with $F(R)=(1-$ $R)^{2} / 2 R ; R$ is the observed reflectance in the DRS; $n=1 / 2$ for an indirect allowed transition, or 2 for a direct allowed transition, in this case $n$ equals $1 / 2$ according to the above calculated results of the band structure for $\mathrm{BaLu}_{2} \mathrm{Si}_{3} \mathrm{O}_{10} ; A$ is the proportional constant; $\nu$ is the photon energy; and $E_{\mathrm{g}}$ is the value of the host bandgap. ${ }^{29}$ By adopting the methods proposed by Cao et al. ${ }^{31}$ the optical bandgap energy of $\mathrm{BaLu}_{2} \mathrm{Si}_{3} \mathrm{O}_{10}$ is determined to be $5.5420 \mathrm{eV}$ by extrapolation to $F(R)=0$. It is expected that
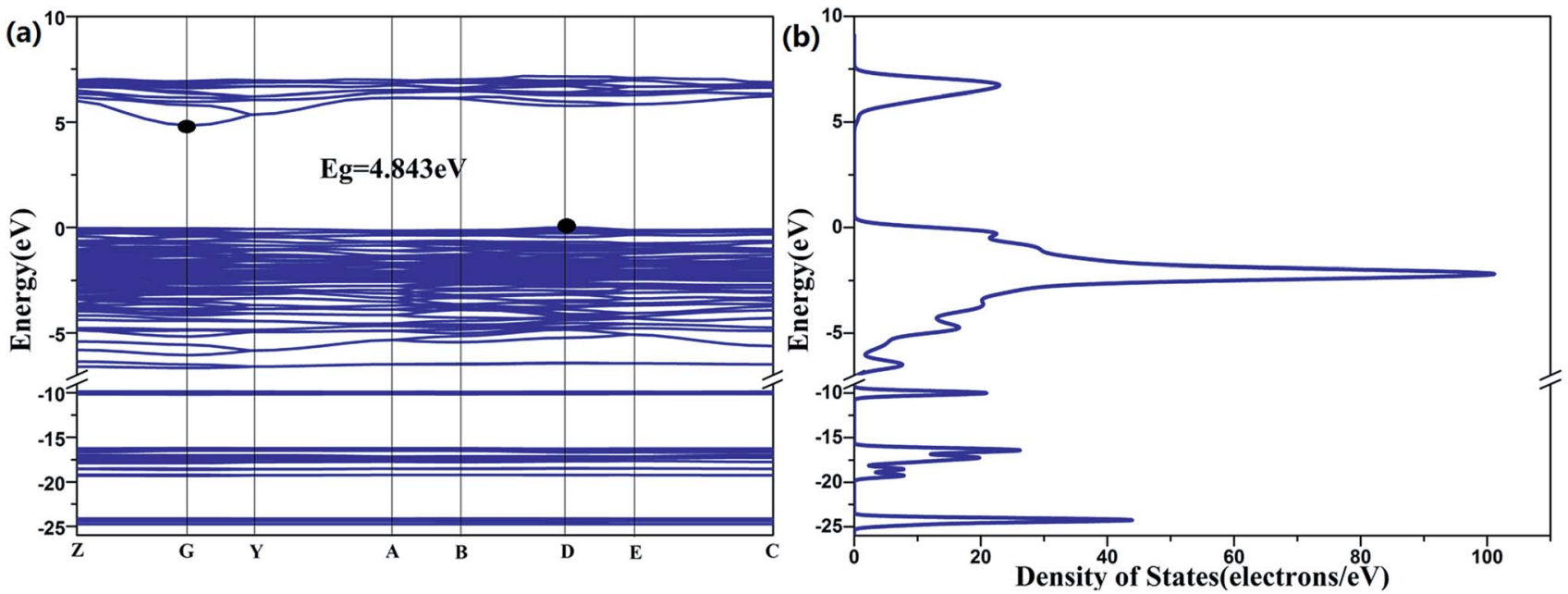

(c)

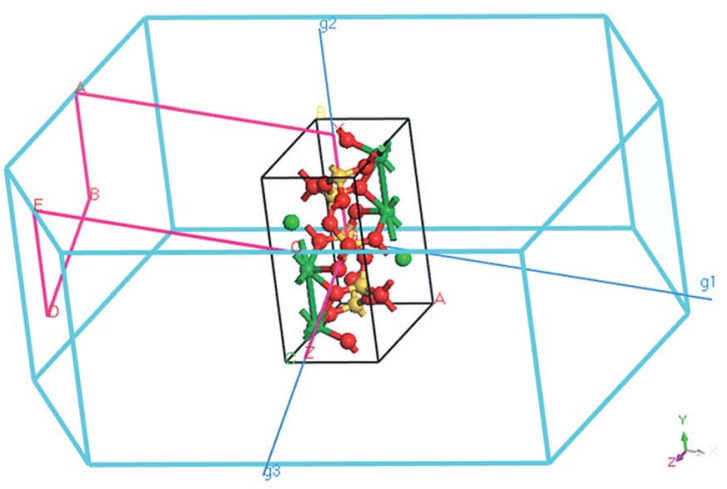

(d)

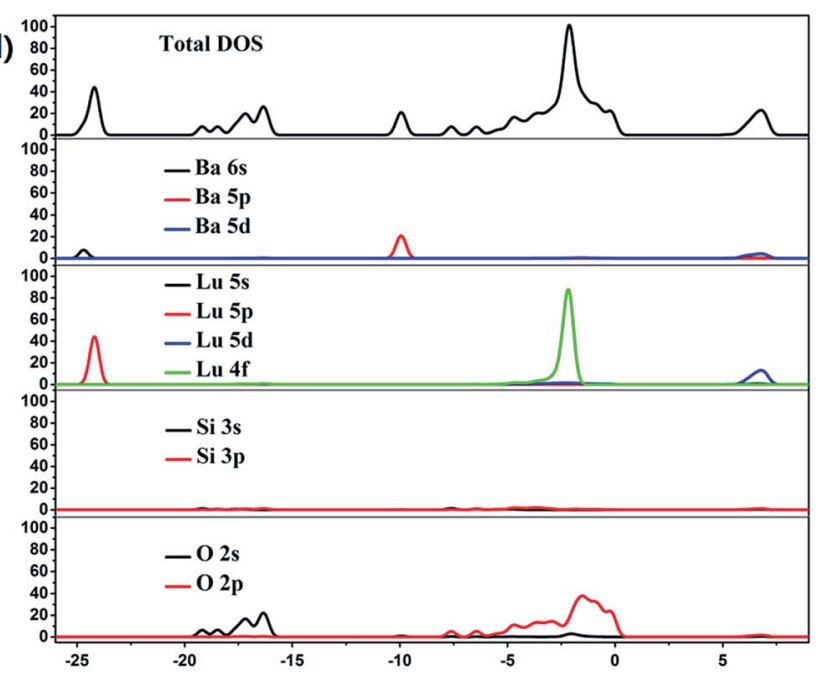

Fig. 3 (a) Band structure of $\mathrm{BaLu}_{2} \mathrm{Si}_{3} \mathrm{O}_{10}$. (b) Density of states. (c) Brillouin zone. (d) Total and partial density of states. 


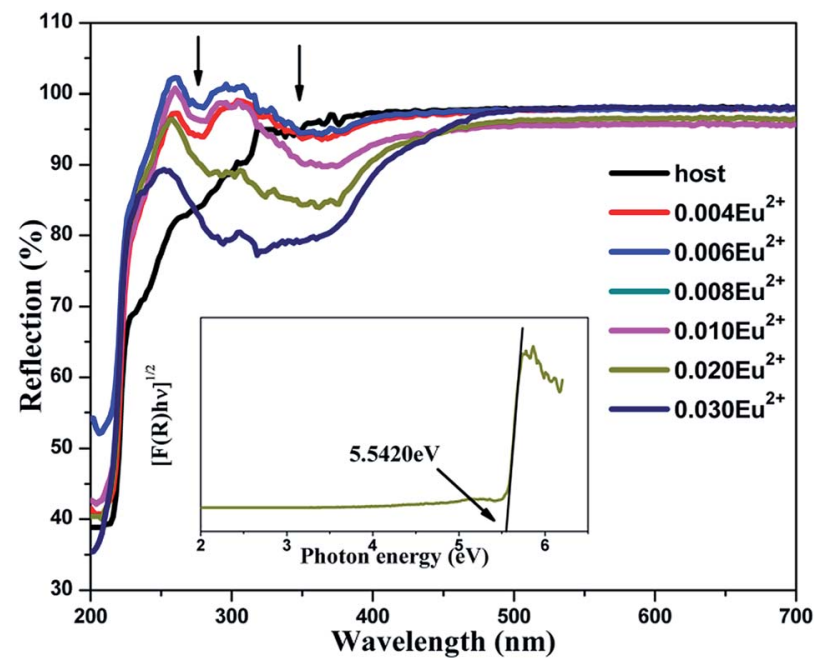

Fig. 4 DRS of the undoped $\mathrm{BaLu}_{2} \mathrm{Si}_{3} \mathrm{O}_{10}$ host and concentration gradient samples of $\mathrm{BaLu}_{2} \mathrm{Si}_{3} \mathrm{O}_{10}: \mathrm{Eu}^{2+}$. (Inset) A curve of $[F(R) \times h \nu]^{1 / 2}$ vs. $h v$ for $\mathrm{BaLu}_{2} \mathrm{Si}_{3} \mathrm{O}_{10}$
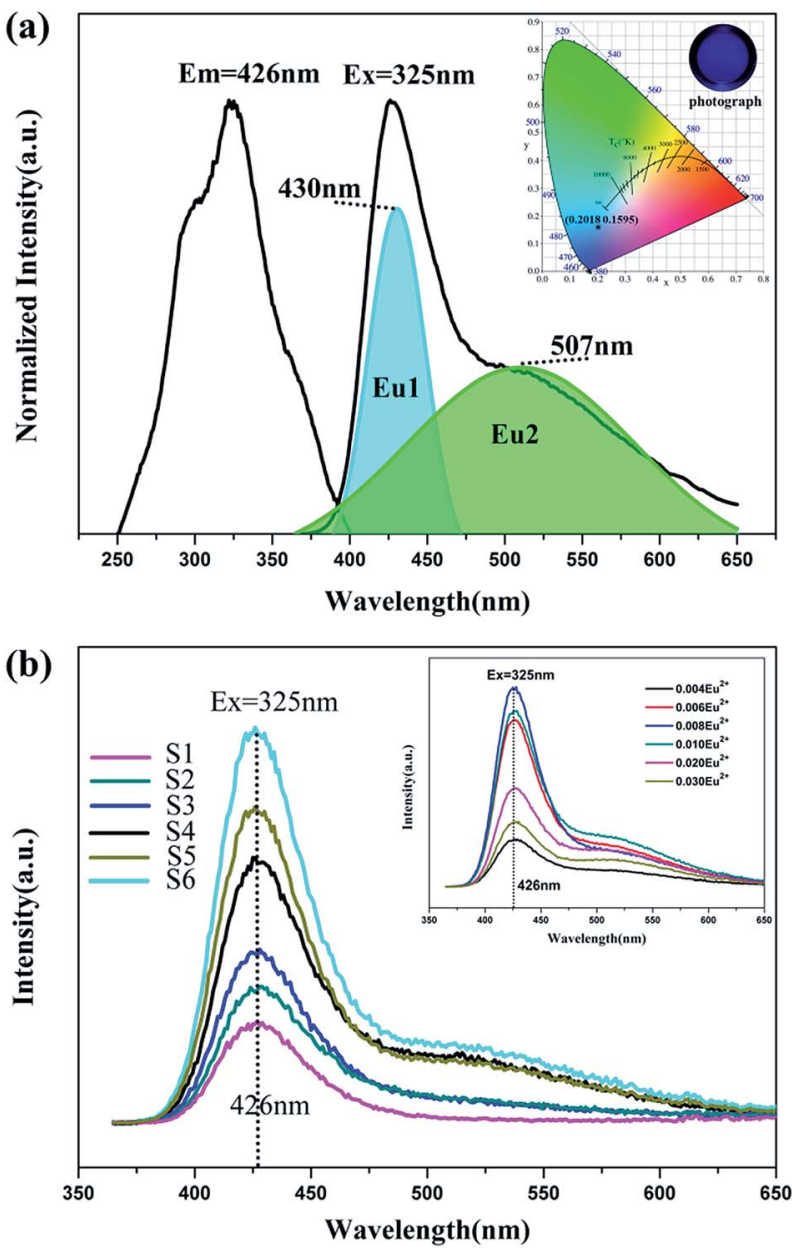

Fig. 5 (a) Excitation and emission spectra of $\mathrm{BaLu}_{2} \mathrm{Si}_{3} \mathrm{O}_{10}: 0.008 \mathrm{Eu}^{2+}$ (Inset) $\mathrm{ClE}$ chromaticity diagram and photographs of the $\mathrm{BaLu}_{2} \mathrm{Si}_{3}$ $\mathrm{O}_{10}: 0.008 \mathrm{Eu}^{2+}, 0.008 \mathrm{Nd}^{3+}$ phosphor excited at $325 \mathrm{~nm}$. (b) Emission spectra of concentration gradient samples of $\mathrm{BaLu}_{2} \mathrm{Si}_{3} \mathrm{O}_{10}: \mathrm{Eu}^{2+}, \mathrm{Nd}^{3+}$. (Inset) Emission spectra of concentration gradient samples of $\mathrm{BaLu}_{2} \mathrm{Si}_{3} \mathrm{O}_{10}: \mathrm{Eu}^{2+}$. the value of the optical bandgap surpasses that of the previously calculated bandgap of approximately $4.843 \mathrm{eV}$ as the localdensity approximation depends less on the bandgap size and spin-orbit coupling of $\mathrm{Lu}^{3+}$ which has not been considered. ${ }^{32}$

\subsection{Photoluminescence and phosphorescence properties}

The emission and excitation spectra for the $\mathrm{BaLu}_{2} \mathrm{Si}_{3} \mathrm{O}_{10}: \mathrm{Eu}^{2+}$ phosphor at room temperature is presented in Fig. 5a. The excitation spectrum that was monitored at $426 \mathrm{~nm}$ shows a broad excitation band ranging from $250 \mathrm{~nm}$ to $400 \mathrm{~nm}$ which arises from the $4 \mathrm{f}^{7}-4 \mathrm{f}^{6} 5 \mathrm{~d}^{1}$ transition of $\mathrm{Eu}^{2+}$ ions. Two primary peaks at $290 \mathrm{~nm}$ and $325 \mathrm{~nm}$ which are contained in the broad band show that $\mathrm{Eu}^{2+}$ ions are present and that their role is as an emission center. In the case of a $325 \mathrm{~nm}$ optimal excitation, the material merely shows one wide asymmetric band with a long shoulder peaking at $426 \mathrm{~nm}$. Such an emission peak arises from the $\mathrm{Eu}^{2+}$ ions undergoing equally allowed electronic $4 \mathrm{f}^{6} 5 \mathrm{~d}^{1}-4 \mathrm{f}^{7}$ transitions, which is considerably affected by the lattice of the host. ${ }^{30}$ In light of calculated results from the empirical equation, it can be deduced that $\mathrm{Eu}^{2+}$ ions only seem to access the $\mathrm{Ba}$ sites. However, on the basis of the analysis performed on the emission and excitation spectra, the incorporated $\mathrm{Eu}^{2+}$ ions could take up both $\mathrm{Lu}$ and $\mathrm{Ba}$ sites in the $\mathrm{BaLu}_{2} \mathrm{Si}_{3} \mathrm{O}_{10}$ host. Accordingly, the emission centers fall into two types. In this regard, this work adopts Gaussian deconvolution which takes into account the emission spectrum of the $\mathrm{BaLu}_{2} \mathrm{Si}_{3} \mathrm{O}_{10}: \mathrm{Eu}^{2+}$ phosphor being widely asymmetric, and the spectrum is compatible with two peaks at $507 \mathrm{~nm}$ and $430 \mathrm{~nm}$. As the higher emission intensity shown by Eu1 in contrast to Eu2 elucidates, the $\mathrm{Eu}^{2+}$ ions preferably take up Ba sites instead of Lu sites. Fig. 5a presents $(0.2018,0.1595)$ as the CIE chromaticity coordinate for $\mathrm{BaLu}_{2} \mathrm{Si}_{3} \mathrm{O}_{10}: \mathrm{Eu}^{2+}$ and blue as the color, which is acquired from the spectrum for emitting light whereby the calculation of the chromaticity coordinate follows the CIE1931 (Commission International de I'Eclairage France) system. As shown in Fig. $5 \mathrm{~b}$ as the concentration of $\mathrm{Nd}^{3+}$ ions increases the emission spectra of $\mathrm{BaLu}_{2} \mathrm{Si}_{3} \mathrm{O}_{10}: \mathrm{Eu}^{2+}, \mathrm{Nd}^{3+}$ merely show one band being asymmetrically wide, which is similar to that of the single doped sample. As shown in Fig. 5b (inset), all doped samples have a broad asymmetric emission peak at $426 \mathrm{~nm}$ with a long shoulder. It also means $\mathrm{Eu}^{2+}$ ions fill both $\mathrm{Ba}$ and $\mathrm{Lu}$ sites. As the doping concentration increases the brightness increases and then decreases and shows $\mathrm{BaLu}_{2} \mathrm{Si}_{3} \mathrm{O}_{10}: 0.008 \mathrm{Eu}^{2+}$ to be the best doped sample. Additionally, this work fails to observe the representative emissions of the $\mathrm{Nd}^{3+}$ ions. As the foregoing results indicate, trivalent lanthanide ions $\mathrm{Nd}^{3+}$ are not deemed emission centers in $\mathrm{BaLu}_{2} \mathrm{Si}_{3} \mathrm{O}_{10}: \mathrm{Eu}^{2+}, \mathrm{Nd}^{3+}$ but are centers for trapping in numerous LLP phosphors. ${ }^{30}$

Fig. 6a shows the phosphorescence spectra of $\mathrm{BaLu}_{2} \mathrm{Si}_{3}-$ $\mathrm{O}_{10}: 0.008 \mathrm{Eu}^{2+}, 0.008 \mathrm{Nd}^{3+}$ at different times after removing the excitation source. Interestingly, the profiles do not change with the phosphorescence decay time, but are greatly different from the emission profiles. This interesting phenomenon indicates that the LLP originates from both emissions $\left(\mathrm{Eu}_{\mathrm{Lu}}\right.$ and $\left.\mathrm{Eu}_{\mathrm{Ba}}\right)$ but they have very different contributions during the LLP process. In Fig. $6 \mathrm{~b}$, the phosphorescence spectrum of $\mathrm{BaLu}_{2} \mathrm{Si}_{3} \mathrm{O}_{10}: 0.008 \mathrm{Eu}^{2+}$, 

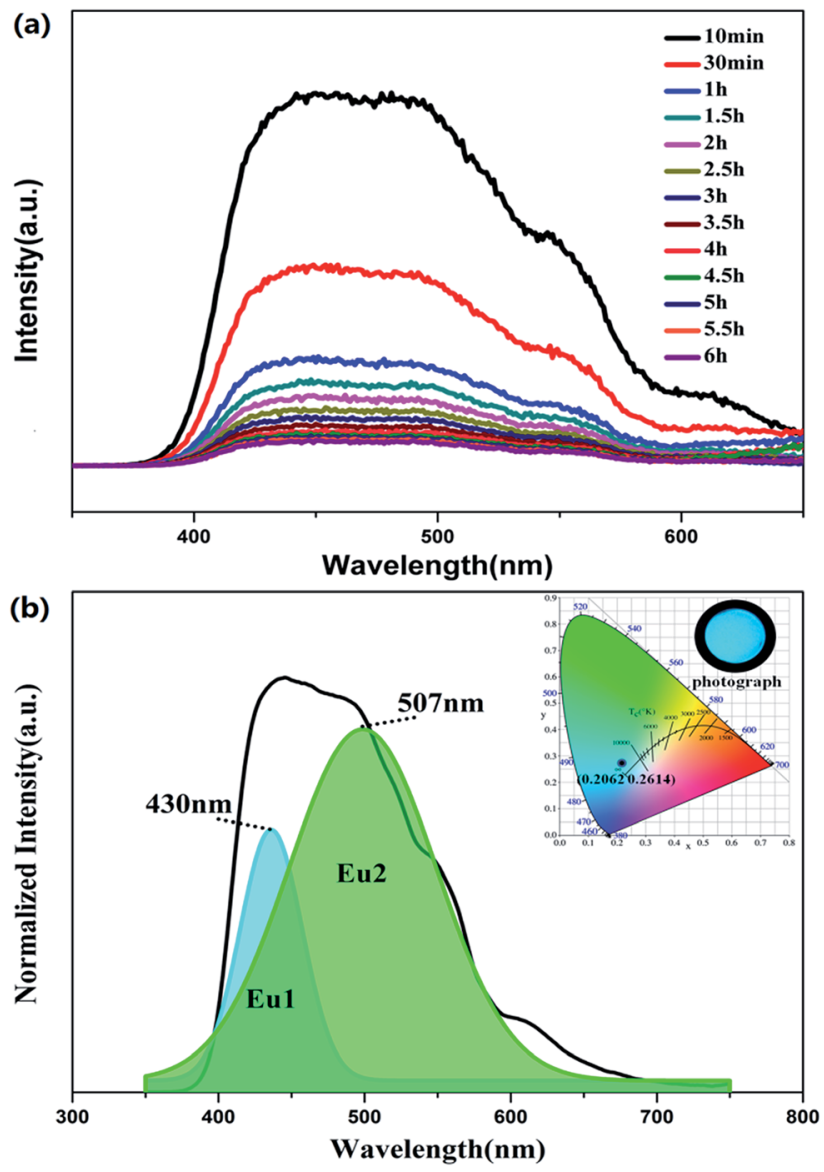

Fig. 6 (a) Phosphorescence spectrum of $\mathrm{BaLu}_{2} \mathrm{Si}_{3} \mathrm{O}_{10}: 0.008 \mathrm{Eu}^{2+}$ $0.008 \mathrm{Nd}^{3+}$. (b) Phosphorescence spectra of $\mathrm{BaLu}_{2} \mathrm{Si}_{3} \mathrm{O}_{10}: 0.008 \mathrm{Eu}^{2+}$ $0.008 \mathrm{Nd}^{3+} 30 \mathrm{~min}$ after the removal of the excitation source. (Inset) $\mathrm{CIE}$ chromaticity diagram and photograph of the phosphorescence spectrum for the $\mathrm{BaLu}_{2} \mathrm{Si}_{3} \mathrm{O}_{10}: 0.008 \mathrm{Eu}^{2+}, 0.008 \mathrm{Nd}^{3+}$ phosphor, excited at $325 \mathrm{~nm}$.

$0.008 \mathrm{Nd}^{3+}$ which was measured $30 \mathrm{~min}$ after the source of excitation was switched off is processed by Gaussian deconvolution and is consistent with two peaks at $430 \mathrm{~nm}$ and $507 \mathrm{~nm}$, which is similar to the PL spectrum. The phosphorescence CIE chromaticity coordinate is $(0.2062,0.2614)$ and the color is bluish-green, as shown in the inset of Fig. 6b. The PL color is blue but the phosphorescence color is bluish-green, indicating that the phosphorescence is derived from the $5 \mathrm{~d}-4 \mathrm{f}$ transition of $\mathrm{Eu}^{2+}$ ions in the $\mathrm{Ba}$ and $\mathrm{Lu}$ sites. $\mathrm{Eu}_{\mathrm{Lu}}$ has a greater contribution during the LLP process, so the color of phosphorescence tends to be green, rather than blue.

\subsection{Luminescence decay curves}

To demonstrate that the phosphorescence stems from the $\mathrm{Eu}_{\mathrm{Lu}}$ emission in the current $\mathrm{BaLu}_{2} \mathrm{Si}_{3} \mathrm{O}_{10}$ host, luminescence decay curves were measured at an excitation of $325 \mathrm{~nm}$ and monitored at 426 and $507 \mathrm{~nm}$. The results are shown in Fig. 7. The luminescence decay curves were able to be adjusted by a doubleexponential mode and the average luminescence decay time $\tau$ could be ascertained from the formula below. ${ }^{33}$

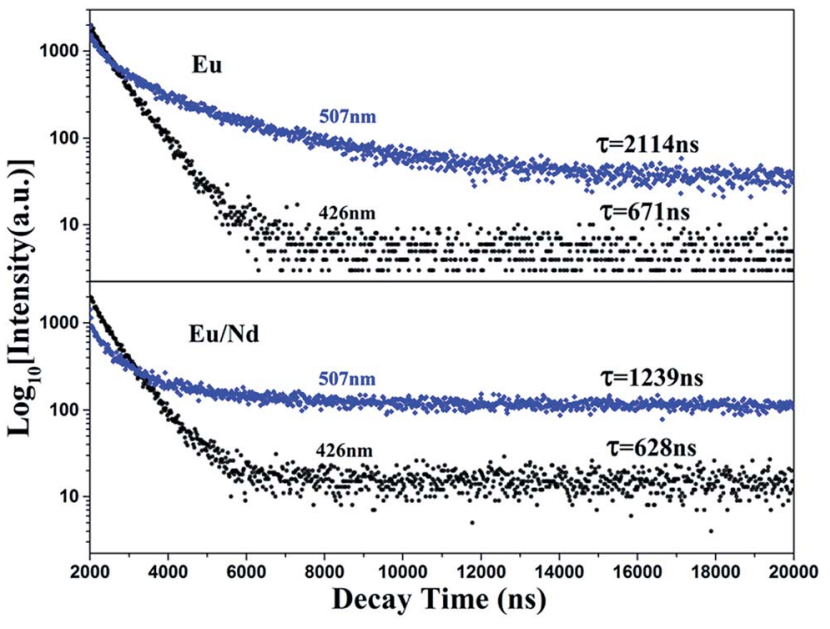

Fig. 7 Luminescence decay curves of $\mathrm{BaLu}_{2} \mathrm{Si}_{3} \mathrm{O}_{10}: \mathrm{Eu}^{2+}$ and $\mathrm{BaLu}_{2}-$ $\mathrm{Si}_{3} \mathrm{O}_{10}: \mathrm{Eu}^{2+}, \mathrm{Nd}^{3+}$ excited at $325 \mathrm{~nm}$ and monitored at $426 \mathrm{~nm}$ and $507 \mathrm{~nm}$.

$$
\tau=\left(A_{1} \tau_{1}^{2}+A_{2} \tau_{2}^{2}\right) /\left(A_{1} \tau_{1}+A_{2} \tau_{2}\right)
$$

where $A_{1}$ and $A_{2}$ are constant and $\tau_{1}$ and $\tau_{2}$ are the two exponential components of the fitting luminescence decay curve. Table 2 lists the fitting parameters specifically. In line with the equation above and the fitting parameters, the average luminescence decay times monitored at 426 and $507 \mathrm{~nm}$ were calculated to be 671 and $2114 \mathrm{~ns}$ for the $\mathrm{BaLu}_{2} \mathrm{Si}_{3} \mathrm{O}_{10}: \mathrm{Eu}^{2+}$ phosphor, and 638 and $1239 \mathrm{~ns}$ for the $\mathrm{BaLu}_{2} \mathrm{Si}_{3} \mathrm{O}_{10}: \mathrm{Eu}^{2+}, \mathrm{Nd}^{3+}$ phosphor, respectively. We found that both the luminescence decay times monitored at 426 and $507 \mathrm{~nm}$ are characteristic of the $5 \mathrm{~d}-4 \mathrm{f}$ allowed transition of $\mathrm{Eu}^{2+}$, indicating that the green phosphorescence at $507 \mathrm{~nm}$ indeed originates from the $\mathrm{Eu}^{2+}$ emission, rather than from some defect levels. ${ }^{34}$ The $\mathrm{Eu}^{2+}$ luminescence decay time decreases with the introduction of $\mathrm{Nd}^{3+}$ ions. The reason is that with the introduction of $\mathrm{Nd}^{3+}$ ions there is an inequivalence of substitution which leads to lattice distortion and causes lots of defects. Those defects could play a role as energy traps, where the energy from $\mathrm{Eu}^{2+}$ ions can transfer. This new approach for energy transfer causes a decrease in the luminescence decay time. Furthermore, the dual-exponential curve fitting arising from the spectral overlap of the two emission bands and can support the statement that $\mathrm{Eu}^{2+}$ occupies both the $\mathrm{Ba}$ and $\mathrm{Lu}$ sites in $\mathrm{BaLu}_{2} \mathrm{Si}_{3} \mathrm{O}_{10}{ }^{30}$

Table 2 The fitting parameters of the luminescence decay curves of $\mathrm{BaLu}_{2} \mathrm{Si}_{3} \mathrm{O}_{10}: \mathrm{Eu}^{2+}$ and $\mathrm{BaLu}_{2} \mathrm{Si}_{3} \mathrm{O}_{10}: \mathrm{Eu}^{2+}, \mathrm{Nd}^{3+}$ excited at $325 \mathrm{~nm}$ and monitored at $426 \mathrm{~nm}$ and $507 \mathrm{~nm}$.

\begin{tabular}{llrrrl}
\hline Sample & $\lambda_{\text {em }}(\mathrm{nm})$ & $\tau_{1}(\mathrm{~ns})$ & $\tau_{2}(\mathrm{~ns})$ & \multicolumn{1}{c}{$A_{1}$} & \multicolumn{1}{c}{$A_{2}$} \\
\hline $\mathrm{Eu}^{2+}$ & 426 & 722.81 & 235.58 & 1438.98 & 524.39 \\
$\mathrm{Eu}^{2+}, \mathrm{Nd}^{3+}$ & 507 & 2618.30 & 470.54 & 545.66 & 930.57 \\
& 526 & 671.06 & 160.98 & 1584.67 & 448.23 \\
& 507 & 1606.05 & 288.46 & 313.56 & 673.59
\end{tabular}




\subsection{LLP decay curves}

As presented in Fig. 8a, this work measured the LLP decay curves for all of the as-synthesized samples (S1-S6) in order to delve into the decay performance of the $\mathrm{BaLu}_{2} \mathrm{Si}_{3} \mathrm{O}_{10}: \mathrm{Eu}^{2+}, \mathrm{Nd}^{3+}$ emission. The decay process of the LLP is encompassed by a slow decay process and a fast decay process. Those fast decay processes occur initially and dominate the intensity at the very beginning, and the slow decay processes occur later which lead to the long term behavior. ${ }^{35-38}$ This work, through adopting curve-fitting technology, analyzes the decay curves of the samples (S1-S6), and these curves are found to adequately match the following double-exponential equation.

$$
I=A_{1} \exp \left(-t / \tau_{1}\right)+A_{2} \exp \left(-t / \tau_{2}\right)+A_{0}
$$

where $I$ is the phosphorescence intensity, $A_{0}, A_{1}$ and $A_{2}$ are constants, $t$ is time, and $\tau_{1}$ and $\tau_{2}$ are the decay times of the exponential components. Since the performance of LLP is chiefly determined by $\tau_{2}{ }^{39}$ the $\tau_{2}$ values for all of the samples are listed in Table 3 . The value of $\tau_{2}$ increases in the beginning and
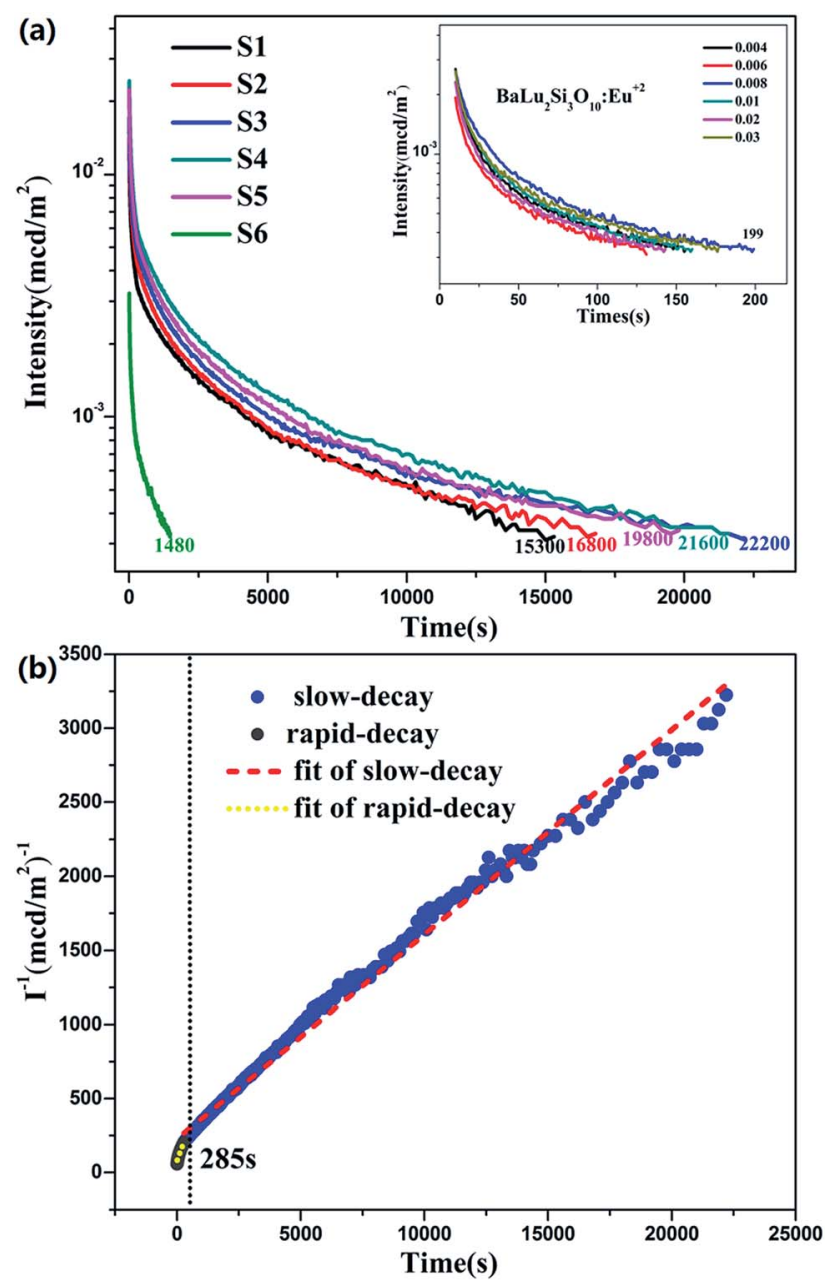

Fig. 8 (a) LLP decay curves of $\mathrm{BaLu}_{2} \mathrm{Si}_{3} \mathrm{O}_{10}: \mathrm{Eu}^{2+}, \mathrm{Nd}^{3+}$. Inset: LLP decay curves of $\mathrm{BaLu}_{2} \mathrm{Si}_{3} \mathrm{O}_{10}: \mathrm{Eu}^{2+}$ (b) function of reciprocal LLP intensity $\left(l^{-1}\right)$ versus time $(t)$ of $\mathrm{BaLu}_{2} \mathrm{Si}_{3} \mathrm{O}_{10}: 0.008 \mathrm{Eu}^{2+}, 0.008 \mathrm{Nd}^{3+}$ excited for $10 \mathrm{~min}$.
Table 3 Decay times for two exponential components of $\mathrm{Ba}_{1-2 x} \mathrm{Lu}_{2}-$ $\mathrm{Si}_{3} \mathrm{O}_{10}: x \mathrm{Eu}^{2+}, x \mathrm{Nd}^{3+}(x=0,0.004,0.006,0.008,0.010 .02$ and 0.03$)$

\begin{tabular}{llllll}
\hline Sample & $A_{0}$ & $A_{1}$ & $\tau_{1}(\mathrm{~s})$ & $A_{2}$ & $\tau_{2}(\mathrm{~s})$ \\
\hline S1 & $7.2266 \times 10^{-4}$ & 0.0110 & 55.5423 & 0.0054 & 1224.0458 \\
S2 & $6.7820 \times 10^{-4}$ & 0.0086 & 62.6299 & 0.0046 & 1242.8820 \\
S3 & $8.3097 \times 10^{-4}$ & 0.0170 & 60.0109 & 0.0065 & 1326.3692 \\
S4 & $6.6350 \times 10^{-4}$ & 0.0093 & 50.3919 & 0.0037 & 1323.1464 \\
S5 & $8.0447 \times 10^{-4}$ & 0.0150 & 55.4197 & 0.0061 & 1191.9548 \\
S6 & $3.9931 \times 10^{-4}$ & 0.0022 & 26.1850 & 0.0012 & 236.5758
\end{tabular}

then decreases later with the increase in $\mathrm{Eu}^{2+}$ and $\mathrm{Nd}^{3+}$ ion content. They reach a maximum when the amount of the $\mathrm{Eu}^{2+}$ and $\mathrm{Nd}^{3+}$ ions reaches $0.008 \mathrm{~mol}$. LLP decay curves of $\mathrm{BaLu}_{2}-$ $\mathrm{Si}_{3} \mathrm{O}_{10}: \mathrm{Eu}^{2+}$ are shown in the inset of Fig. 8a. The values peak when there is $0.008 \mathrm{~mol}$ of $\mathrm{Eu}^{2+}$ ions. The initial LLP intensity of $\mathrm{BaLu}_{2} \mathrm{Si}_{3} \mathrm{O}_{10}: 0.008 \mathrm{Eu}^{2+}, 0.008 \mathrm{Nd}^{3+}$ is in the vicinity of $0.013 \mathrm{~cd}$ $\mathrm{m}^{-2}$ and its LLP can continue in excess of $6 \mathrm{~h}$ over an intensity level which is able to be recognized $\left(0.32 \mathrm{mcd} \mathrm{m}^{-2}\right)$. The phosphorescence of $\mathrm{BaLu}_{2} \mathrm{Si}_{3} \mathrm{O}_{10}: 0.008 \mathrm{Eu}^{2+}$ is only visible for $199 \mathrm{~s}$ by the naked eye, which indicates that the introduction of $\mathrm{Nd}^{3+}$ ions greatly optimizes the phosphorescence of $\mathrm{BaLu}_{2} \mathrm{Si}_{3}$ $\mathrm{O}_{10}: 0.008 \mathrm{Eu}^{2+}$. The LLP decay curve of $\mathrm{BaLu}_{2} \mathrm{Si}_{3} \mathrm{O}_{10}: 0.008 \mathrm{Eu}^{2+}$, $0.008 \mathrm{Nd}^{3+}$ is also plotted as a function of reciprocal persistent luminescence intensity $\left(I^{-1}\right)$ versus time $(t)$, as presented in Fig. $8 \mathrm{~b}$. The detailed reasons are discussed later in the section on TL curves.

\subsection{Thermoluminescence curves}

Trapping centers play a momentous role in the photo-energy storage of persistent and thermo-stimulated phosphors. ${ }^{40}$ After removal of the excitation source, the captured charge carriers are able to escape due to thermal disturbance and are transferred to centers for luminescence, which triggers the phosphorescence. Accordingly, shallow depth traps are negatively and adversely affected by stabilizing the charge carriers, which considerably shortens the duration period of persistent luminescence. In contrast, the charge carriers that are captured by deep depth traps are extremely hard to release at room temperature, which leads to the defective performance of the LLP. $^{\text {40-42 }}$ For this reason, as the appropriate trap depth is formed, a solid foundation is laid for attaining a perfect LLP performance. Meanwhile, the trap density is also a significant factor for LLP. To characterize the traps in our samples TL measurements were conducted on $\mathrm{BaLu}_{2} \mathrm{Si}_{3} \mathrm{O}_{10}: 0.008 \mathrm{Eu}^{2+}$ and $\mathrm{BaLu}_{2} \mathrm{Si}_{3} \mathrm{O}_{10}: 0.008 \mathrm{Eu}^{2+}, 0.008 \mathrm{Nd}^{3+}$, their TL curves are shown in Fig. 9, we only observe three very weak peaks in $\mathrm{BaLu}_{2} \mathrm{Si}_{3}$ $\mathrm{O}_{10}: \mathrm{Eu}^{2+}$ and it is possible that the TL bands arise from intrinsic defects in the host as the $\mathrm{Eu}^{2+}$ ions are equally replaced by $\mathrm{Ba}^{2+}$ ions in $\mathrm{BaLu}_{2} \mathrm{Si}_{3} \mathrm{O}_{10}$. Additionally, as the weak TL signal indicates, the concentration of carriers that is captured by the intrinsic defects is extremely low. When $\mathrm{Nd}^{3+}$ ions are co-doped, the intensity of the peaks are evidently enhanced, and the primary peak position moves to $330 \mathrm{~K}$, meaning that the doping of the $\mathrm{Nd}^{3+}$ ions considerably elevates the defect levels. To further evaluate the trap states, the trap depths $\left(E_{\mathrm{t}}\right)$ and the trap densities $\left(n_{0}\right)$ can be acquired from eqn (4) and (5). ${ }^{43}$ 


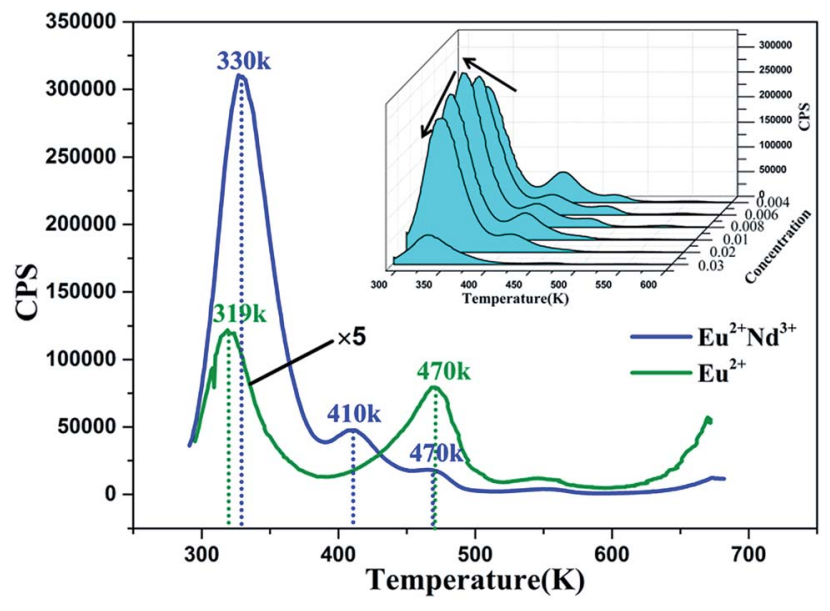

Fig. $9 \mathrm{TL}$ curves of $\mathrm{BaLu}_{2} \mathrm{Si}_{3} \mathrm{O}_{10}: 0.008 \mathrm{Eu}^{2+}, 0.008 \mathrm{Nd}^{3+}$ excited for 25 min. Inset: concentration gradient TL curves of $\mathrm{BaLu}_{2} \mathrm{Si}_{3} \mathrm{O}_{10}: \mathrm{Eu}^{2+}$, $\mathrm{Nd}^{3+}$ excited for $5 \mathrm{~min}$.

$$
\begin{gathered}
E_{\mathrm{t}}=\left[2.52+10.2 \times\left(\mu_{\mathrm{g}}-0.42\right)\right] \times\left(K_{\mathrm{B}} T_{\mathrm{m}}{ }^{2} / \omega\right)-2 K_{\mathrm{B}} T_{\mathrm{m}} \\
n_{0}=\omega I_{\mathrm{m}} /\left\{\beta \times\left[2.52+10.2 \times\left(\mu_{\mathrm{g}}-0.42\right)\right]\right\}
\end{gathered}
$$

Where $I_{\mathrm{m}}$ is the intensity of the TL peak, $\delta$ is the hightemperature half-width, $\tau$ is the low-temperature half-width, the asymmetry parameter $\mu_{\mathrm{g}}=\delta /(\tau+\delta), \beta$ is the heating rate, $K_{\mathrm{B}}$ is the Boltzmann constant $\left(1.38 \times 10^{-23} \mathrm{~J} \mathrm{~K}^{-1}\right), T_{\mathrm{m}}$ is the temperature of the TL peak, and $\omega$ is known as the shape parameter and is defined as $\omega=\tau+\delta$. As shown in Table 4 , for the $\mathrm{BaLu}_{2} \mathrm{Si}_{3} \mathrm{O}_{10}: 0.008 \mathrm{Eu}^{2+}$ sample, although the trap depth is appropriate for releasing the trapped carriers, the low trap density directly results in a brief LLP of $199 \mathrm{~s}$. For $\mathrm{BaLu}_{2} \mathrm{Si}_{3}$ $\mathrm{O}_{10}: 0.008 \mathrm{Eu}^{2+}, 0.008 \mathrm{Nd}^{3+}$, by co-doping with $\mathrm{Nd}^{3+}$ ions, more traps are generated with a suitable energy depth which greatly improves the duration of the LLP and the LLP brightness in the very beginning. This result suggests that co-doping indeed has a great effect upon the LLP performance of the phosphor.

\subsection{LLP mechanism}

Under normal conditions, for the majority of LLP materials, the color of the phosphorescence is identical to the color of the PL arising from the identical emission centers. Yet the blue emitting phosphors show a phosphorescence which is characterized as bluish-green in this paper. In line with the previous analysis, $\mathrm{Eu}^{2+}$ ions which occupy $\mathrm{Ba}$ and $\mathrm{Lu}$ sites serve as emission centers and $\mathrm{Nd}^{3+}$ ions which take up Ba sites serve as trapping

Table $4 \mathrm{TL}$ parameters of $\mathrm{BaLu}_{2} \mathrm{Si}_{3} \mathrm{O}_{10}: 0.008 \mathrm{Eu}^{2+}$ and $\mathrm{BaLu}_{2} \mathrm{Si}_{3}-$ $\mathrm{O}_{10}: 0.008 \mathrm{Eu}^{2+}, 0.008 \mathrm{Nd}^{3+}$

\begin{tabular}{llllllllll}
\hline & \multicolumn{3}{l}{ Glow-peak parameters } & & \multicolumn{2}{l}{ TL parameters } \\
\cline { 2 - 5 } Sample & $T_{\mathrm{m}}(K)$ & $T$ & $\delta$ & $\omega$ & $\mu_{\mathrm{g}}$ & & $E_{\mathrm{t}}(\mathrm{eV})$ & $n_{0}$ \\
\hline $\mathrm{Eu}^{2+}$ & 319 & 19 & 23 & 42 & 0.55 & 0.75 & $2.65 \times 10^{5}$ \\
$\mathrm{Eu}^{2+}, \mathrm{Nd}^{3+}$ & 330 & 21 & 27 & 48 & 0.56 & 0.71 & $3.75 \times 10^{6}$
\end{tabular}

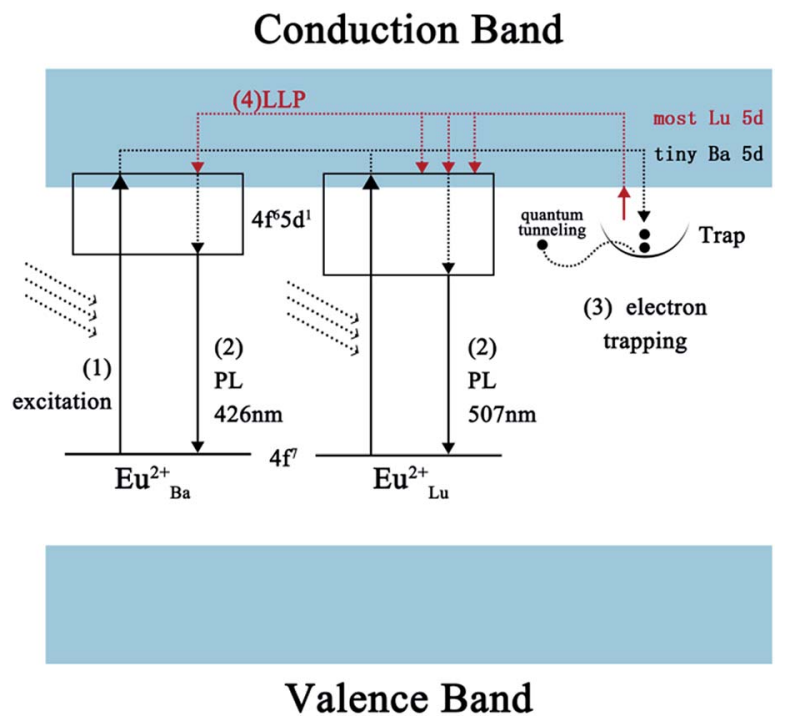

Fig. 10 A possible schematic diagram of the afterglow mechanism.

centers in the co-doped samples. As these experiments overall indicate, this material provides highly-efficient trapping conditions. A probable LLP mechanism for forming the efficient bluish-green LLP in $\mathrm{Eu}^{2+}$ and $\mathrm{Nd}^{3+}$ co-doped $\mathrm{BaLu}_{2} \mathrm{Si}_{3} \mathrm{O}_{10}$ is shown in Fig. 10. Under UV excitation, the $4 \mathrm{f}^{7}$ ground-state electrons of the $\mathrm{Eu}^{2+}$ ions are promoted to the $4 \mathrm{f}^{6} 5 \mathrm{~d}^{1}$ excited state (excitation process 1). Partial electrons which are promptly excited are reincorporated with the $\mathrm{Eu}^{2+}$ ions excited on the Ba and Lu sites to produce luminescence (PL process 2). As most $\mathrm{Eu}^{2+}$ ions occupy the Ba sites and tiny $\mathrm{Eu}^{2+}$ ions occupy the $\mathrm{Lu}$ sites, the phosphor emits blue light. Simultaneously other excited electrons are able to move via the conduction band and are captured later by the traps (electron trapping process 3 ). When the electrons captured by shallow traps are thermally released at room temperature, they move back to the conduction band directly and a few of the captured electrons in deep traps escape through a quantum tunneling process. In view of the conduction band primarily being formed by $\mathrm{Lu} 5 \mathrm{~d}$ states rather than Ba states, the released electrons prefer to transfer to the excited $\mathrm{Eu}^{2+}$ ions on the Lu sites which are in the same form of resonance and recombine with them, which gives rise to the green phosphorescence (LLP process 4). In short, it is the special form of the conduction band and the occupation situation of the emission centers that result in the interesting optical phenomenon.

\section{Conclusions}

In a nutshell, a newly proposed bluish-green emitting longlasting phosphor with prominent LLP properties is successfully achieved via a high temperature solid state method. $\mathrm{Eu}^{2+}$ ions show a broad asymmetric emission band with a peak at $426 \mathrm{~nm}$ as it occupies both the $\mathrm{Ba}$ and $\mathrm{Lu}$ sites in $\mathrm{BaLu}_{2} \mathrm{Si}_{3} \mathrm{O}_{10}$. The blue emitting phosphors show a kind of green phosphorescence phenomenon, which is induced mostly by the emission of $\mathrm{Eu}^{2+}$ ions occupying the $\mathrm{Lu}$ sites. Co-doping with $\mathrm{Nd}^{3+}$ 
ions can effectively improve the LLP performance. The LLP can last more than $6 \mathrm{~h}$ above the recognizable intensity level (0.32 mcd $\mathrm{m}^{-2}$ ). This work also provides direct experimental evidence that the conduction band is of critical significance for the course of LLP. And the analysis regarding this experimental work backs up the LLP mechanism. This new LLP material exhibits a $6 \mathrm{~h}$ LLP and has considerable potential for extensive applications.

\section{Conflicts of interest}

There are no conflicts to declare.

\section{Acknowledgements}

This work is supported by the National Natural Science Funds of China (Grant No. 51672115 and Grant No. 51372105). Thanks for the support of Chengguan district Lanzhou city science and technology development projects (project number: 2017-2-2).

\section{Notes and references}

1 Z. Pan, Y. Y. Lu and F. Liu, Nat. Mater., 2012, 11, 58-63.

2 C. N. Xu, T. Watanabe, M. Akiyama and X. G. Zheng, Appl. Phys. Lett., 1999, 74, 2414-2416.

3 D. Q. Chen, Y. Chen, H. W. Lu and Z. G. Ji, Inorg. Chem., 2014, 53, 8638-8645.

4 D. Q. Chen, J. Eur. Ceram. Soc., 2014, 34, 4069-4075.

5 T. Maldiney, C. Richard, D. Scherman and D. Gourier, Chem. Mater., 2014, 26, 1365-1373.

6 J. Wang, Q. Su and S. B. Wang, J. Phys. Chem. Solids, 2005, 66, 1171-1176.

7 S. Lian, Y. Qi, C. Rong, L. Yu, A. Zhu, D. Yin and S. Liu, J. Phys. Chem. C, 2010, 114, 7196-7204.

8 B. Wang, H. Lin, Y. L. Yu, D. Q. Chen, R. Zhang, J. Xu and Y. S. Wang, J. Am. Ceram. Soc., 2014, 97, 2539-2545.

9 T. Matsuzawa, Y. Aoki, N. Takeuchi and Y. Murayama, J. Electrochem. Soc., 1996, 143, 2670-2673.

10 H. J. Guo, W. B. Chen, W. Zeng and Y. H. Wang, J. Mater. Chem. C, 2015, 22, 5844-5850.

11 Z. Hong, P. Zhang, X. Fan and M. Wang, J. Lumin., 2007, 124, 127-132.

12 V. K. Van den Eeckhout, P. F. Smet and D. Poelman, J. Lumin., 2009, 129, 1140-1143.

13 T. Matsuzawa, Y. Aoki, N. Takeuchi and Y. Murayama, J. Electrochem. Soc., 1996, 143, 2670-2673.

$14 \mathrm{H}$. Yamamoto and T. Matsuzawa, J. Lumin., 1997, 72-74, 287-289.

15 I. P. Sahu, D. P. Bisen, N. Brahme, L. Wanjari and R. K. Tamrakar, Res. Chem. Intermed., 2015, 41, 8797-8814.

16 P. J. Wang, X. H. Xu, D. C. Zhou, X. Yu and J. B. Qiu, Inorg. Chem., 2015, 54, 1690-1697.
17 T. L. Barry, J. Electrochem. Soc., 1968, 115, 1181-1183.

18 Y. Lin, Z. Zhang, Z. Tang, X. Wang and Z. Zheng, J. Eur. Ceram. Soc., 2001, 21, 683-685.

19 M. Wierzbicka-Wieczorek, U. Kolitsch and E. Tillmanns, Eur. J. Mineral., 2010, 22, 245.

20 Q. Wang, G. Zhu, S. Y. Xin, X. Ding, J. Xu, Y. S. Wang and Y. H. Wang, Phys. Chem. Chem. Phys., 2015, 17, 27292-27299.

21 J. Q. Wang, W. R. Zhao, J. M. Zhong and L. C. Lan, J. Mater. Sci.: Mater. Electron., 2014, 25, 2162-2168.

22 J. Zhou and Z. G. Xia, J. Mater. Chem. C, 2015, 3, 7552-7560.

23 W. R. Liu, C. C. Lin, Y. C. Chiu, Y. T. Yeh, S. M. Jang, R. S. Liu and B. M. Cheng, Opt. Express, 2009, 17, 18103-18109.

24 J. Zhou and Z. G. Xia, Opt. Mater., 2016, 52, 116-122.

25 J. Brgoch, K. Hasz, K. A. Denault, C. K. H. Borg, A. A. Mikhailovsky and R. Seshadri, Faraday Discuss., 2014, 176, 333-347.

26 K. Li, S. S. Liang, H. Z. Lian, M. M. Shang, B. G. Xing and J. Lin, J. Mater. Chem. C, 2016, 4, 3443-3453.

27 P. Dorenbos, J. Phys.: Condens. Matter, 2003, 15, 8417.

28 M. Y. Peng, Z. W. Pei, G. Y. Hong and Q. Su, J. Mater. Chem., 2003, 13, 1202-1205.

29 R. D. Shannon, Acta Crystallogr., 1976, 32, 751-767.

30 G. Li, Y. H. Wang, H. J. Guo, J. Liu, D. W. Liu and P. Feng, J. Lumin., 2017, 192, 98-104.

31 G. Cao, L. K. Rabenberg, C. M. Nunn and T. E. Mallouk, Chem. Mater., 1991, 3, 149-156.

32 Y. Q. Li, Y. H. Wang, X. H. Xu, G. Yu and F. Zhang, J. Electrochem. Soc., 2010, 157, 39-43.

33 N. Ruelle, M. P. Thi and C. Fouassier, Jpn. J. Appl. Phys., 1992, 31, 2786-2790.

34 C. Y. Liu, Z. G. Xia, Z. P. Lian, J. Zhou and Q. F. Yan, J. Mater. Chem. C, 2013, 1, 7139-7147.

35 J. Zhang, X. Ma, Q. Qin, L. Shi, J. Sun, M. Zhou, B. Liu and Y. Wang, Mater. Chem. Phys., 2012, 136, 320-324.

36 J. Wang, S. Wang and Q. Su, J. Mater. Chem., 2004, 14, 25692574.

37 R. Pang, C. Li, L. Shi and Q. Su, J. Phys. Chem. Solids, 2009, 70, 303-306.

38 B. Lei, H. Zhang, W. Mai, S. Yue, Y. Liu and S. Man, Solid State Sci., 2011, 13, 525-528.

39 T. Wang, Y. H. Hu, L. Chen, X. J. Wang and G. F. Ju, Radiat. Meas., 2015, 73, 7-13.

40 J. Glodo and A. Wojtowicz, J. Alloys Compd., 2000, 300, 289294.

41 T. Aitasalo, P. Deren, J. Hölsä, H. Junger, J. C. Krupa, M. Lastusaari, J. Legendziewicz, J. Niittykoski and W. Strek, J. Solid State Chem., 2003, 171, 114-122.

42 T. Kinoshita, M. Yamazaki, H. Kawazoe and H. Hosono, J. Appl. Phys., 1999, 86, 3729-3733.

43 R. Chen, J. Appl. Phys., 1969, 40, 570-585. 